\title{
Characteristics of a manta ray Manta alfredi population off Maui, Hawaii, and implications for management
}

\author{
Mark H. Deakos ${ }^{1,2, *}$, Jason D. Baker ${ }^{3}$, Lars Bejder $^{4}$ \\ ${ }^{1}$ The Hawaii Association for Marine Education and Research, Inc., PMB\#175, 5095 Napilihau St. 109B, Lahaina, Hawaii 96761, USA \\ ${ }^{2}$ University of Hawaii at Manoa, 2500 Campus Road, Honolulu, Hawaii 96822, USA \\ ${ }^{3}$ Pacific Islands Fisheries Science Center, National Marine Fisheries Service, NOAA, 2570 Dole Street, Honolulu, \\ Hawaii 96822-2396, USA \\ ${ }^{4}$ Cetacean Research Unit, Centre for Fish and Fisheries Research, Murdoch University, South Street, Murdoch 6150 \\ Western Australia, Australia
}

\begin{abstract}
Late maturity, few offspring and a residential nature are typical characteristics of Manta alfredi that make this species vulnerable to localized anthropogenic threats. Improving its life history information is crucial for successful management. A total of 229 surveys was conducted from 2005 to 2009 at a manta ray aggregation site off Maui, Hawaii, to qualitatively and quantitatively describe the abundance, movements and temporal habits of this population. Photo-identifications revealed 290 unique individuals, but a discovery curve showed no asymptotic trend, indicating that the number of individuals using the area was much larger. Resightings and manta ray follows revealed that this population and a population off the Big Island may be independent, island-associated stocks. High resighting rates within and across years provided strong evidence of site fidelity. Findings were consistent with a population of manta rays moving into and out of the Maui aggregation area, with a varying portion of the total population temporarily resident at any given time. Males, accounting for $53 \%$ of all individuals, resided for shorter periods than females around the study area. Manta rays were usually absent at first light with numbers increasing throughout the day. More frequent mating trains were observed during the winter months. Shark predation was evident in 33\% of individuals, and $10 \%$ had an amputated or non-functional cephalic fin. This small, demographically independent population appears vulnerable to the impacts from non-target fisheries, primarily from entanglement in fishing line, and could suffer from exploitation by commercial, unregulated 'swim-with manta ray' programs. Management on an island-area basis is recommended.
\end{abstract}

KEY WORDS: Population size $\cdot$ Movement $\cdot$ Site fidelity $\cdot$ Mark recapture $\cdot$ Anthropogenic threat Resale or republication not permitted without written consent of the publisher

\section{INTRODUCTION}

Understanding the basic biology and ecology of a species is necessary for its proper conservation and management. For elasmobranchs, which are slowgrowing, slow to mature and have low fecundity (Holden 1974), understanding how populations are affected by anthropogenic impacts is especially important, as they are less likely to recover from population depletion (Hoenig \& Gruber 1990, Pratt \& Casey 1990). Furthermore, populations that are isolated geographically are subject to regional ecological pressures and may require a management strategy that is tailored to that specific population. Batoids (rays) are among the most susceptible marine taxa to fisheries exploitation (Dulvy \& Reynolds 2002, Dulvy et al. 2008); because their large body size is associated with later maturation they face greater risks of overexploitation, extirpation 
and, in some cases, extinction. Manta rays (Manta spp.), the largest of the batoids, may be especially vulnerable.

The status of most manta ray populations worldwide is poorly understood. They are classified by the IUCN Red List for Threatened Animals as 'near-threatened' (Marshall et al. 2006). Fisheries targeting manta rays in many parts of the world (Notarbartolo-di-Sciara 1987, Compagno 1999, Dewar 2002, Marshall et al. 2006) are fueled by an increasing demand for branchial filter plates and cartilage. The branchial filter plates are used in traditional Chinese medicines, and the cartilage is used as filler in shark-fin soup (Alava et al. 2002, Musick \& McMillan 2002, White et al. 2006). These directed fisheries have caused significant population declines in areas such as Mexico (Homma et al. 1999), the Philippines (Alava et al. 2002), Indonesia (Dewar 2002, White et al. 2006), India, Sri Lanka and other parts of Southeast Asia (Marshall et al. 2006).

Manta rays are ovoviviparous, giving birth to a single pup every 2 to 3 yr (Homma et al. 1999, Marshall \& Bennett 2010). The only manta ray birth ever witnessed was captured on video at the Okinawa Churaumi Aquarium in Japan (Uchida et al. 2008). The mother gave birth to a single pup following a 12 mo gestation period. Parturition was immediate and the mother was observed mating within a few hours after giving birth.

Mating behavior in manta rays has been described as a mating train, where multiple males pursue and attempt to mate with a single female (Yano et al. 1999). Although these mating trains can be observed at all times of the year, seasonal peaks have been reported for the summer months (July-August) in Ogasawara, Japan (Yano et al. 1999), and the austral summer (October-November) in Mozambique (Marshall \& Bennett 2010).

The number of species within the Manta genus has long been debated among scientists (Whitley 1936, Beebe \& Tee-Van 1941, Fowler 1941, Bigelow \& Schroeder 1953, Compagno 1984, Nelson 1984, Nishida 1990, Last \& Stevens 1994, Clark 2001) but recent evidence supports at least 2 species: Manta birostris and Manta alfredi (Marshall et al. 2009). M. birostris is the larger of the 2 species, found in tropical, subtropical and temperate waters. Although occasionally seen visiting shallow coastal areas, they spend the majority of their time in pelagic waters, migrating over thousands of kilometers (A. D. Marshall pers. comm.). Their disc width (DW; measured from wing tip to wing tip) can span $6.7 \mathrm{~m}$ (Bigelow \& Schroeder 1953), with 1 specimen reportedly as large as $9.1 \mathrm{~m}$ (Last \& Stevens 1994). M. alfredi are more likely to be observed in shallow coastal areas around rocky and coral reef habitats where productive upwellings exist. They can be found in tropical and subtropical regions of the Pacific,
Atlantic and Indian Oceans within $30^{\circ}$ of latitude to the north and south of the equator (Marshall et al. 2009). Congregations can occur around rich food sources or at specific locations on the reef known as cleaning stations (Losey 1972), where individuals solicit host cleaner fish to remove parasitic copepods from their body's surface. Strong site fidelity occurring at specific feeding and cleaning stations (e.g. Homma et al. 1999) has created popular tourist attractions where visitors pay to swim or SCUBA dive with manta rays (Clark 2001, Dewar et al. 2008). M. alfredi are much smaller than their oceanic cousins, with females reaching a maximum DW between $3.6 \mathrm{~m}$ (Deakos 2010) and $5.5 \mathrm{~m}$ (Marshall et al. 2009) depending on the region. The maximum lifespan is unknown but the longest reported time period between first and last sightings of M. alfredi is $27 \mathrm{yr}(1980-2006)$ off Yaeyama Island, Japan (Kashiwagi et al. 2008).

For management purposes, differentiating between Manta birostris and M. alfredi is extremely important because each species could be exposed to a very different set of anthropogenic impacts. Although $M$. birostris may be targeted by large-scale directed fisheries, or succumb to bycatch in longline and tuna purse seine operations (Paulin et al. 1982, Romanov 2002), M. alfredi populations may be more vulnerable to nearshore anthropogenic impacts such as coastal development, storm water runoff, pollutant loadings, boat strikes, entanglement in fishing and mooring lines, and increased pressure from 'swim-with manta' programs. A basic understanding of the abundance, home range and use of popular aggregation areas by $M$. alfredi is needed for effective management.

The aim of the present study was to use photo-identification and active tracking to qualitatively and quantitatively describe the abundance, movements, population structure, and daily and seasonal habits of Manta alfredi frequenting a known aggregation area in waters off West Maui, Hawaii. In addition, natural and anthropogenic threats affecting this population were investigated and quantified, and their implications for management are discussed.

\section{MATERIALS AND METHODS}

Main study area. All surveys were conducted at a manta aggregation area off the west coast of the island of Maui, Hawaii. The exact location of the site is being withheld to avoid the potential commercial exploitation of this unique site. The monitoring boundary for the study site comprised an area $\sim 30000 \mathrm{~m}^{2}(200 \times$ $150 \mathrm{~m}$ ) in size, $450 \mathrm{~m}$ offshore, with a depth range of 5 to $30 \mathrm{~m}$ (Fig. 1). This area was chosen because of the high reliability of encountering manta rays, thereby 
maximizing encounter rates. Habitat consisted primarily of fringing coral reef that extended away from the shoreline for $\sim 550 \mathrm{~m}$. The main cleaning stations were situated near the starting point of the survey where manta rays have been seen soliciting predominantly Hawaiian cleaner wrasses Labroides phthirophagus and saddle wrasses Thalassoma duperrey to remove parasitic copepods from their body surface. Mating trains were also observed in this area.

Surveys. Surveys, carried out with open-circuit SCUBA, were conducted opportunistically over a 5 yr period between 2005 and 2009. Surveys were done at different times of the day and attempts were made to conduct at least 1 survey during each month of each year. Because of an apparent diurnal trend on manta ray sighting rates, $10 \mathrm{~d}$ in which a pair of surveys were conducted in a single day were compared using a Wilcoxon signed-rank test to determine whether sighting rates later in the day were significantly different from those earlier in the day. The majority of surveys were conducted during late afternoon because more manta rays were likely to be encountered during that time.

Each survey involved a 55 to 75 min SCUBA dive. Divers entered the water from the beach and transited at the surface $450 \mathrm{~m}$ to the survey start point before descending (Fig. 1). A dive flag was attached to the ocean floor in $10 \mathrm{~m}$ of water. Midway down the tether, a fluorescent green target $(30 \times 20 \mathrm{~cm})$ was attached and used as a visual cue to determine visibility. The distance at which the target was no longer visible was recorded from the north and south of the flag and the mean was used as the visibility rating for that survey.

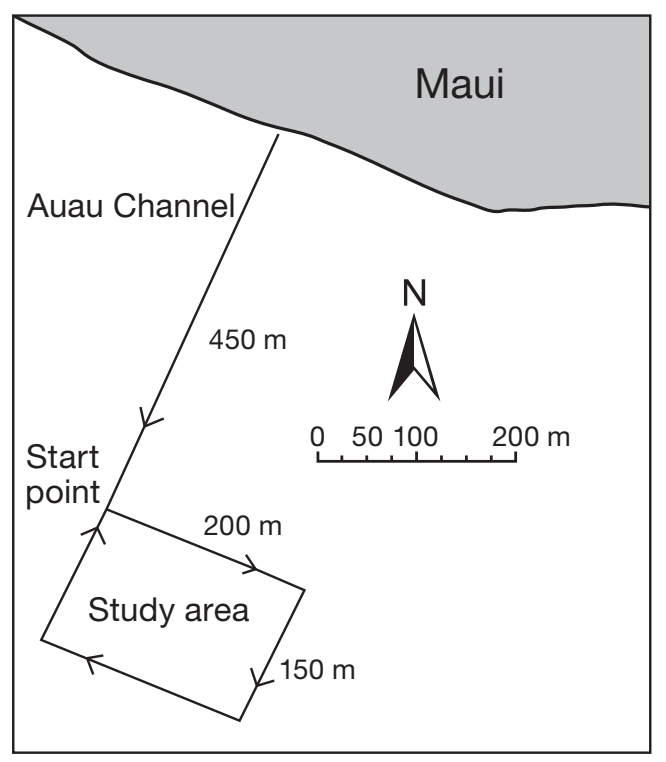

Fig. 1. Manta alfredi. Maui aggregation area
A rectangular search pattern was initiated from the start point (see Fig. 1). When manta rays were encountered, the search was interrupted in order to collect information on that individual. Once the desired information was collected, the search pattern was resumed.

Photo-identification. Photo-identification involves taking photographs of distinctive characteristics of an animal in order to identify and track individuals of a wild population over time. This technique has been used extensively with large and long-lived vertebrates (for a review see Würsig \& Jefferson 1990) for population estimates (e.g. Graham \& Roberts 2007) and information on life history (e.g. Brault \& Caswell 1993), lifespan (e.g. Langtimm et al. 2004), migration patterns (e.g. Calambokidis et al. 1996) and social relationships (e.g. Bejder et al. 1998). Each manta ray is born with a unique pattern of spots on its ventral side (Marshall et al. 2008) that appears to remain unchanged for the duration of the animal's life (Yano et al. 1999, Clark 2001, Marshall \& Bennett 2010), even after 20 yr (Homma et al. 1999). This makes manta rays highly suitable for photo-identification studies.

During each manta ray encounter, a diver equipped with either a Canon Powershot S70 in an underwater housing or a Sony HDR-HC1 video camera in a Sea \& Sea VX-HC1 underwater housing attempted to photograph the ventral pattern of each individual sighted. The best identification for each individual was imported into FinBase, a publicly available photo-identification program created in Microsoft Access (Adams et al. 2006). The photo was matched against photos of all previously identified individuals from the study site and recorded as either a match or a new individual. The very distinct markings on the underside of each manta ray make the likelihood of missing or falsely identifying a match very unlikely.

Abundance and survivorship. Discovery curve: To illustrate the rate at which new individuals were encountered, a discovery curve showing the cumulative number of individual manta rays identified was plotted against the cumulative number of identifications made. Winter and summer seasonal identifications were differentiated on the curve to visually demonstrate whether new individuals were entering the population more often during a particular season.

Mark-recapture modeling: Given the nature of the study site (a cleaning station that manta rays visit) and the 5 yr duration of the survey period, we cannot assume that the population was closed during the entire study. That is, animals probably moved into and out of the study area, and we expect that there were both mortalities and recruitment of new individuals (through births) throughout the study period. We could not reasonably assume closure for even a single year. Therefore, we identified 5 sampling periods ( 1 in each 
calendar year), during which there was relatively intensive survey effort in a relatively short time span (74 to 127 d, Fig. 2). We assumed population closure within these periods and estimated abundance using the program CAPTURE, run within the program MARK interface (Otis et al. 1978, Rexstad \& Burnham 1991). Intervals were selected to include the largest number of surveys within the shortest time periods throughout the $5 \mathrm{yr}$ of the study. CAPTURE applies a testing algorithm to determine which of a suite of models (involving combinations of time-varying capture probability, behavioral response to capture, and heterogeneity effects) is most appropriate for a given set of capture histories. Estimates were obtained using the model type assigned the highest rank by the algorithm.

In addition to the population closure assumption, other assumptions included that marked animals did not lose their marks during the study and that all marks were correctly recorded (Otis et al. 1978). The highly distinct and permanent marks on the study animals conformed to these assumptions. Estimates of abundance were generated separately for males and females in each time period. Therefore, we generated separate estimates of abundance for males and females in each time period. These abundance estimates can be interpreted as the number of manta rays using the study area within each period rather than a total population abundance estimate.

Apparent survival: Estimates of apparent survival rates (1 - [mortality + emigration]) and capture probabilities were obtained using the 'recaptures only' analysis implemented in MARK (White \& Burnham 1999).
This extended the basic Cormack-Jolly-Seber fully time-dependent model to evaluate a categorical factor (gender) (Lebreton et al. 1992). We fitted models with time-variant and constant survival and capture probabilities as well as separate and combined gender models. These were ranked and their support evaluated using the small-sample Akaike's information criterion $\left(\mathrm{AIC}_{c i}\right.$ see Anderson et al. 2000).

Assumptions of the capture-recapture survival analysis were similar to those for abundance estimation as described above. Additionally, we assumed equal probability of capture among marked individuals. By collapsing all sighting efforts within a sampling period to a single event (seen or not seen), heterogeneity in capture probability was reduced. Capture heterogeneity was further addressed by explicitly modeling differences in sightability among sexes and years, so that constant capture probability need only be assumed within these strata (Lebreton et al. 1992). The final assumption required is that all samples are collected instantaneously, relative to the interval for which survival is estimated. Although this assumption is never literally met in a wildlife study, the survey period should be short relative to the survival interval. In this way the survival estimation intervals are of equal duration and there is reduced chance of any mortality occurring within a resighting period. In our case, resighting effort was spread unevenly and at all times of year so that we could not use all the data without grievously violating the instantaneous sampling assumption. Instead, we used only the resighting data from the same relatively intensive survey periods used to estimate abundance.

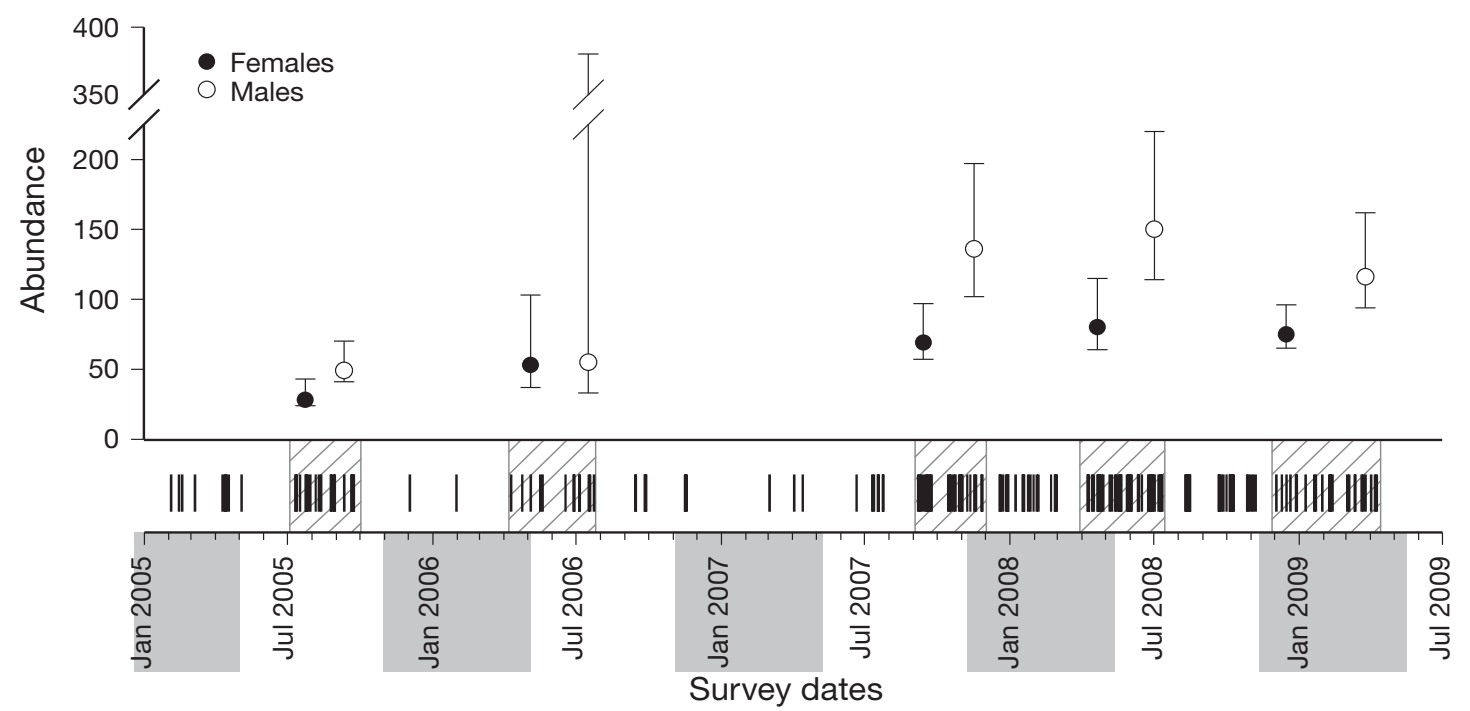

Fig. 2. Manta alfredi. Manta ray dive survey effort, sampling periods selected for abundance estimation, and abundance estimates. The timeline areas shaded in gray indicate 'winter' (November through April) and unshaded areas indicate 'summer' (May through October) as defined for this study. Vertical black lines above the $x$-axis indicate individual dive surveys, with hatched boxes encompassing the 5 periods in which abundance estimates for male and female manta rays (with 95\% confidence intervals) were obtained 
To account for the temporal irregularity of these periods, in MARK we specified the time intervals between sampling periods as the time (in years) between median survey dates of consecutive periods. By doing so, the resulting survival estimates were standardized as annual.

Individual movements. Acoustic tracking: Two manta rays were tagged, each with a Vemco V16 continous acoustic pinger. Each pinger was programmed to emit a unique pulse frequency (52 and $56 \mathrm{kHz}$, respectively). The signal was received through a VH110 directional hydrophone (frequency range 50 to $84 \mathrm{kHz}$ ) and decoded by a Vemco VR100 receiver/decoder that was kept onboard a $28 \mathrm{ft}$ Glass Pro vessel. A crew of 3 rotated every $4 \mathrm{~h}$ tracking the manta ray in real time from the vessel. Tracking was continuous throughout the day and night until weather conditions made it unsafe to continue. The acoustic detection range of the pingers was $\sim 1 \mathrm{~km}$. A continuous track of the boat was recorded onto a Garmin GPSMAP 276C. The acoustic tags were attached to the dorsal side of the right pectoral fin by a snorkeler swimming above the manta ray. The tags were deployed using a modified Hawaiian sling and anchored to the manta ray by embedding a small stainless steel barb under the skin. The barb was tethered to the acoustic tag with $15 \mathrm{~cm}$ of stainless steel wire and crimps.

Regional comparisons: Photo-identifications from our study area were compared with opportunistic photo-identifications taken of manta rays off the southwestern coast of Maui $(\mathrm{n}=18)$, Molokini Crater $(\mathrm{n}=11)$ and the southeastern coast of Molokai ( $\mathrm{n}=11)$. Comparisons were also made with a catalog of 146 individual manta rays from a well-monitored population off Kona on the Island of Hawaii (Big Island) (www. mantapacific.org), to look for potential movements between Maui and the Big Island.

Population structure. Gender was determined by the presence of claspers in males, and their absence in females. A chi-square statistic was used to compare the male/female sex ratio with parity. Females were only classified as sexually mature if they had visible mating scars (spot scarring and abrasions usually on the dorsal or ventral side of the left wing tip) or were obviously pregnant (Marshall \& Bennett 2010). Pregnant females close to term were exceptionally rotund and unmistakable. Females that appeared to be pregnant but were questionable were not given an age class.

Among males, calcification of the claspers occurs rapidly over a relatively narrow range of growth (White et al. 2006) and the majority of calcification occurs once the claspers have extended beyond the length of the pelvic fins (Marshall \& Bennett 2010). Because the onset of clasper calcification in many shark species coincides with a rapid rate of clasper growth and gonadal maturation (e.g. Jones et al. 2008), claspers extended beyond the pelvic fins were used as a reliable indicator of sexual maturity in male manta rays. As juvenile females could not be determined, comparisons between adults and juveniles were done only with males.

Use of the aggregation area. Temporal trends: Sighting rates were computed as the total number of manta rays photo-identified divided by the number of hours surveyed. These rates were compared by time of day, month, season and year. The start time of each survey was categorized as morning (06:00 to 10:00 h), midday (10:00 to 14:00 h) or afternoon (14:00 to 18:00 h). Surveys from November through April were categorized as winter surveys and surveys from May through October were categorized as summer surveys. The effect of diver visibility and tidal state on sighting rate was also examined. Linear regression was used to determine the correlation between sighting rates and diver visibility. A Kruskal-Wallis test was used to assess the significance of year, season, month and tidal state in explaining variance of manta ray sightings. Tide tables were used to determine the tidal state, which was categorized as incoming (flood tide), incoming/ outgoing (high tide), outgoing (ebb tide) or outgoing/ incoming (low tide) for each survey.

Residency: A lag identification rate (LIR) is the probability of identifying an individual given its identification some time lag earlier (Whitehead 2007). These were estimated to explore possible differences in residency patterns between adult male and female manta rays in the study area. The LIR for a given lag $(t)$ is the probability that an individual identified at any time ' 0 ' is re-identified at $t$ units later:

$$
R(t)=P(t) / N
$$

where $R(t)$ is the LIR for time lag $t, P(t)$ is the probability that an animal is in the study area $t$ time units after it was there and $N$ is the population size in the study area (Whitehead 2001).

All LIR estimates were calculated using the software SOCPROG 2.3 (Whitehead 2009). Four models of residency were fitted to the residency data using quasi AIC (QAIC) methods to determine the best model. QAIC model fitting was chosen over AIC model-fitting because of variance overdispersion (Whitehead 2007). The 4 models fitted were (1) a closed model (assumes that there are no changes in the individuals present in the study area); (2) an emigration model (assumes that individuals could leave the study area but never return); (3) a model that allows for emigration and reimmigration; and (4) a model that allows for emigration, re-immigration and mortality.

Reproduction and new individuals: The presence or absence of mating trains and pregnant females were recorded for each survey as well as the proportion of males to females. Chi-square statistics were used to 
compare the proportion of mating trains between winter and summer seasons. The mean number of new individual sighting rates (total number of newly identified individuals divided by the total amount of time surveyed) was computed for each survey, by month, season and year. A Kruskal-Wallis Test was used to test the significant difference in the rate of new individuals occurring by month and season.

Threats. Physical characteristics of an individual were also recorded and included (1) missing or damaged cephalic fin, and/or (2) the presence of a large wound, large scar or large section of the body missing (i.e. disc or tail), indicative of having been attacked by a large predator. Chi-square statistics were used to compare the proportions of natural and anthropogenic injuries between gender and age class. The probability level at which significance was determined was 0.05 . Statistical analyses were performed using SPSS version 17.0.

\section{RESULTS}

\section{Surveys}

A total of 229 surveys were conducted between 2005 and 2009 (Table 1). Surveys carried out later in the day were more likely to have a higher sighting rate (Wilcoxon signed-rank, $Z=-2.912, \mathrm{n}=20, \mathrm{p}=0.004$ ). Because of this diurnal trend, the majority of dives were conducted in the afternoon $(82 \%)$ in order to increase encounter rates. The remaining surveys were conducted in the morning $(8 \%)$ and at midday $(10 \%)$. We conducted $57 \%$ of surveys in the summer months and $43 \%$ during winter months. A total of 1494 manta rays were encountered and photo-identified, revealing 290 unique individuals. Manta rays were observed in $201(88 \%)$ surveys. The number of manta rays encountered during each survey ranged from 0 to 31 .

Table 1. Manta alfredi. Number of surveys conducted and mean sighting rates for 2005-2009, broken down into time of day (morning: 06:00-10:00 $\mathrm{h}_{\text {; }}$ midday: 10:00-14:00; afternoon: 14:00-16:00 h) and season (winter: Nov-Apr; summer: May-Oct). Sighting rates are calculated as the mean number of manta rays observed per hour of survey effort

\begin{tabular}{|lccccccc|}
\hline \multirow{2}{*}{ Year } & \multicolumn{7}{c|}{ No. of surveys } \\
\cline { 2 - 7 } & \multirow{2}{*}{ Morning } & Midday & Afternoon & Winter & Summer & Total \\
\hline 2005 & 0 & 0 & 33 & 10 & 23 & 33 \\
2006 & 1 & 1 & 22 & 6 & 18 & 24 \\
2007 & 16 & 14 & 29 & 22 & 37 & 59 \\
2008 & 1 & 8 & 86 & 42 & 53 & 95 \\
2009 & 0 & 1 & 17 & 18 & 0 & 18 \\
Overall & 18 & 24 & 187 & 98 & 131 & 229 \\
Sighting rate & 1.40 & 4.17 & 6.90 & 8.14 & 4.77 & 6.21 \\
\hline
\end{tabular}

\section{Abundance and survivorship}

Discovery curve

The discovery curve (Fig. 3) illustrates a decreasing trend of new individuals entering the population with increasing identifications. The curve has a steep slope during early surveys and begins to decrease with additional surveys, but never reaches an asymptote.

\section{Mark recapture}

Abundance estimates for males, females and total individuals visiting the study area during the 5 different sampling periods for 2005-2009 are listed in Table 2. The sampling periods comprised 74, 105, 81, 95 and $127 \mathrm{~d}$, respectively, for each of these years. The abundance estimates exhibited some notable patterns (Fig. 2). In each period, more males were estimated to be using the study site than females, though it should be noted that the estimates for males tended to have greater uncertainty. The number of manta rays using the area appeared to increase during the third through the fifth period (2007-2009) compared with the first and second (2005-2006), again with the caveat of large variances in the male estimates. Capture histories for most data sets analyzed indicated capture heterogeneity amongst individuals and varying capture probability over time.

\section{Apparent survival}

Models with all combinations of constant, timedependent and sex-specific apparent survival and capture probability parameters were fitted in MARK to capture histories of 238 manta rays, the number of unique individuals captured during the sampling periods. The model fit and selection results for the top 4 models are listed in Table 3. The topranked model had time-varying survival and capture probability included as parameters. A model with sex differences in capture probabilities was essentially equally well supported, but the apparent survival estimates from both these models were almost exactly the same, so the simpler model was selected. Parameter estimates from this model are listed in Table 4.

Because the best model was time dependent in both survival and recapture probabilities, the parameters for 


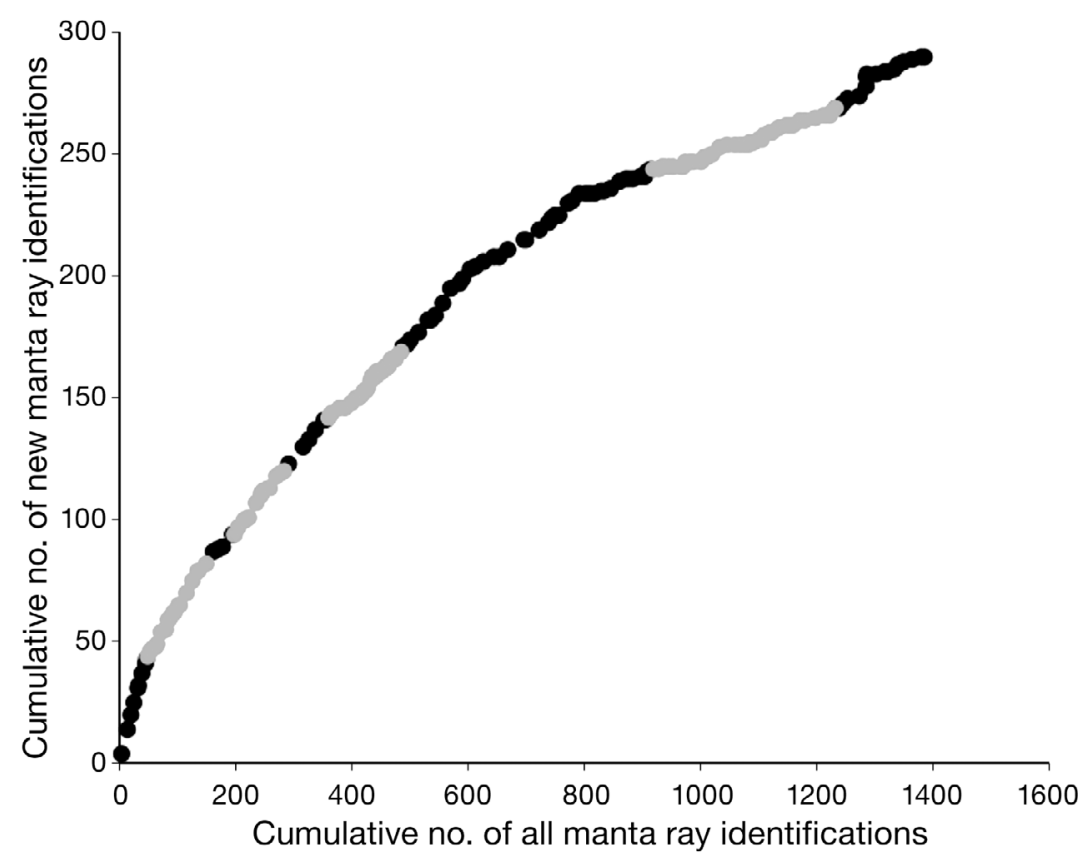

Fig. 3. Manta alfredi. Cumulative number of new manta ray identifications against the cumulative number of all identifications. $=$ winter surveys (November-April), $\bigcirc=$ summer surveys (May-October) abilities lower than 1.0, estimated survival from the second to third sampling period was 1.0. The drop in apparent survival to 0.68 between the third and fourth period might reflect real increases in mortality or emigration, but may also be influenced by limited opportunity for back calculation that might have occurred with additional effort beyond the fifth survey period.

\section{Individual movements}

\section{Acoustic tracking}

On separate occasions in December 2008, an adult male and an adult female manta ray were tagged with an acoustic transmitter in the study area. Both animals were in a mating train at the time of tagging. The adult male was tracked for $28 \mathrm{~h}$ and traveled across the Auau channel to the north coast of the island of Lanai, a linear distance of $40 \mathrm{~km}$ from the study area survival to, and recapture rate during, the final period were confounded and not estimable. However, apparent survival was estimated for 3 intervals (Table 4) and was quite high for the first two. A total of 59 manta rays were identified during the second period, of which 52 were subsequently seen. Accounting for capture probwhere he was tagged (Fig. 4). The maximum depth traversed was $93 \mathrm{~m}$. The adult female was tracked for $51 \mathrm{~h}$ and traveled to the northwest side of the island of Kahoolawe, a linear distance of $32 \mathrm{~km}$ from the study area where she was tagged (Fig. 4). The maximum depth traversed was $324 \mathrm{~m}$.

Table 2. Manta alfredi. Manta ray capture-recapture abundance estimated using Program CAPTURE during 5 sampling periods. Estimates for females (F) and males (M) were separately obtained. 'Identified' = number of unique individuals photographically identified during each sampling period. 'Model' = selected Program CAPTURE model type and notation following Otis et al. (1978), subscripts denote models with constant capture probability (o), capture heterogeneity (h), time-dependent capture probability (t), behavioral response to capture (b) or a combination. ' $\mathrm{p}$ ' = the constant, average or range of estimated capture probabilities (depending upon the model) during individual dive surveys. Estimated abundance $\left(N_{\text {est }} \pm\right.$ SD), lower (LCL) and upper (UCL) confidence intervals are presented

\begin{tabular}{|c|c|c|c|c|c|c|c|}
\hline Period & Sex & Identified & Model & $\mathrm{p}$ & $N_{\text {est }}$ & LCL & $\mathrm{UCL}$ \\
\hline 11 Jul-23 Sep 2005 & $\begin{array}{c}\mathrm{F} \\
\mathrm{M} \\
\text { All }\end{array}$ & $\begin{array}{l}22 \\
34 \\
56\end{array}$ & $\begin{array}{l}\mathrm{M}_{\mathrm{h}} \\
\mathrm{M}_{\mathrm{o}} \\
\mathrm{M}_{\mathrm{t}}\end{array}$ & $\begin{array}{l}0.08 \\
0.06\end{array}$ & $\begin{array}{l}28 \pm 4.3 \\
49 \pm 7.1 \\
77 \pm 8.3\end{array}$ & $\begin{array}{l}24 \\
41\end{array}$ & $\begin{array}{l}43 \\
70\end{array}$ \\
\hline 10 Apr-24 Jul 2006 & $\begin{array}{l}\mathrm{F} \\
\mathrm{M} \\
\text { All }\end{array}$ & $\begin{array}{l}28 \\
31 \\
59\end{array}$ & $\begin{array}{l}\mathrm{M}_{\mathrm{t}} \\
\mathrm{M}_{\mathrm{tb}}\end{array}$ & $\begin{array}{l}0.00-0.15 \\
0.00-0.16\end{array}$ & $\begin{array}{r}53 \pm 15.2 \\
55 \pm 56.2 \\
108 \pm 58.2\end{array}$ & $\begin{array}{l}37 \\
33\end{array}$ & $\begin{array}{l}103 \\
380\end{array}$ \\
\hline 7 Sep-27 Nov 2007 & $\begin{array}{l}\mathrm{F} \\
\mathrm{M} \\
\text { All }\end{array}$ & $\begin{array}{c}46 \\
57 \\
103\end{array}$ & $\begin{array}{l}M_{h} \\
M_{h}\end{array}$ & $\begin{array}{l}0.05 \\
0.02\end{array}$ & $\begin{array}{c}69 \pm 9.8 \\
136 \pm 23.7 \\
205 \pm 25.6\end{array}$ & $\begin{array}{c}57 \\
102\end{array}$ & $\begin{array}{c}97 \\
197\end{array}$ \\
\hline 8 Apr-12 Jul 2008 & $\begin{array}{l}\mathrm{F} \\
\mathrm{M} \\
\text { All }\end{array}$ & $\begin{array}{c}51 \\
76 \\
127\end{array}$ & $\begin{array}{l}\mathrm{M}_{\mathrm{h}} \\
\mathrm{M}_{\mathrm{tb}}\end{array}$ & $\begin{array}{c}0.03 \\
0.01-0.07\end{array}$ & $\begin{array}{r}80 \pm 12.3 \\
150 \pm 25.9 \\
230 \pm 28.7\end{array}$ & $\begin{array}{c}64 \\
114\end{array}$ & $\begin{array}{l}115 \\
220\end{array}$ \\
\hline 3 Dec 2008-9 Apr 2009 & $\begin{array}{l}\mathrm{F} \\
\mathrm{M} \\
\text { All }\end{array}$ & $\begin{array}{c}54 \\
71 \\
125\end{array}$ & $\begin{array}{l}\mathrm{M}_{\mathrm{t}} \\
\mathrm{M}_{\mathrm{tb}}\end{array}$ & $\begin{array}{l}0.00-0.16 \\
0.01-0.17\end{array}$ & $\begin{array}{c}75 \pm 7.8 \\
116 \pm 16.9 \\
191 \pm 18.6\end{array}$ & $\begin{array}{l}65 \\
94\end{array}$ & $\begin{array}{c}96 \\
162\end{array}$ \\
\hline
\end{tabular}


Table 3. Manta alfredi. Model fit and selection results for manta ray apparent survival analysis during 5 sampling periods. The 4 top-ranked models are shown. The first 2 columns indicate model structure in terms of how survival and recapture probability were modeled (allowing time variance, sex-specific rates, or both). Model selection was based on small sample corrected Akaike's information criterion $\left(\mathrm{AIC}_{\mathrm{c}}\right)$

\begin{tabular}{|lccccc|}
\hline Survival & Capture probability & $\mathrm{AIC}_{\mathrm{c}}$ & $\Delta \mathrm{AIC}_{\mathrm{c}}$ & $\mathrm{AIC}_{\mathrm{c}}$ weight & Parameters \\
\hline Time & Time & 830.769 & 0 & 0.471 & 5 \\
Time & Time $\times$ Sex & 831.038 & 0.269 & 0.412 & 8 \\
Time $\times$ Sex & Time $\times$ Sex & 834.167 & 3.398 & 0.086 & 10 \\
Time $\times$ Sex & Time & 836.294 & 5.525 & 0.030 & 9 \\
\hline
\end{tabular}

Table 4. Manta alfredi. Apparent survival and recapture estimates of manta rays from the top ranked model in Table 3. Estimates, standard errors (SE), lower (LCL) and upper (UCL) confidence intervals are shown

\begin{tabular}{|lcccc|}
\hline & Estimate & SE & LCL & UCL \\
\hline Survival & & & & \\
1st to 2nd period & 0.948 & 0.035 & 0.821 & 0.987 \\
2nd to 3rd period & 1.000 & 0.000 & 1.000 & 1.000 \\
3rd to 4th period & 0.683 & 0.058 & 0.562 & 0.784 \\
Recapture probability & & & & \\
2nd period & 0.677 & 0.055 & 0.562 & 0.774 \\
3rd period & 0.638 & 0.044 & 0.547 & 0.719 \\
4th period & 0.909 & 0.038 & 0.801 & 0.961 \\
\hline
\end{tabular}

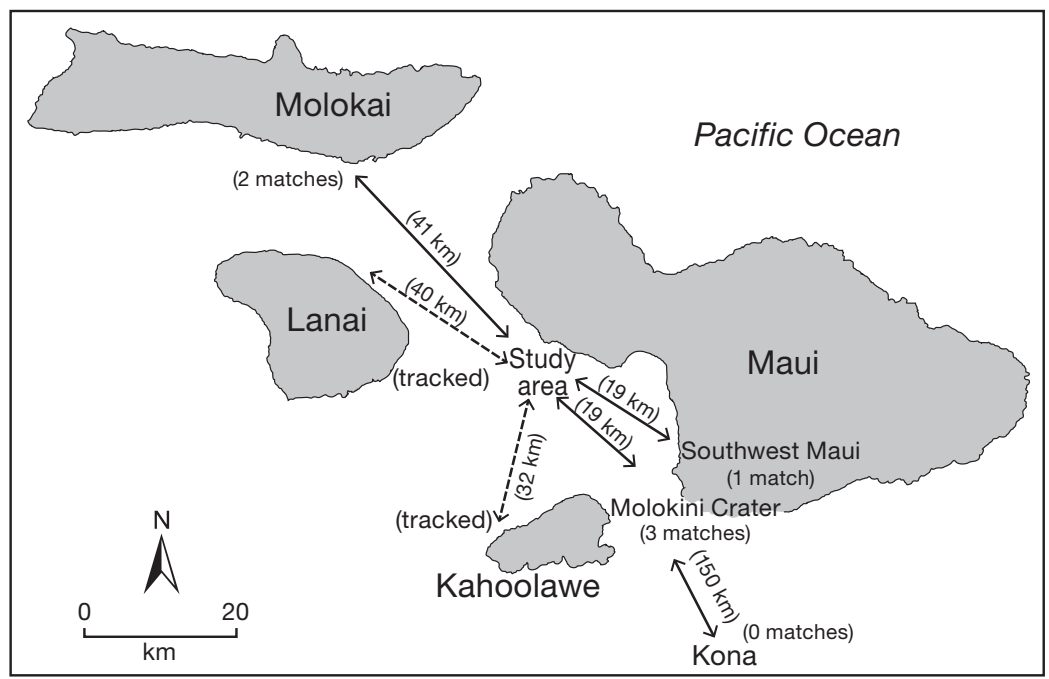

Fig. 4. Manta alfredi. Range of individuals either matched with photoidentifications or tracked with an acoustic tag

\section{Regional comparisons}

Of the 290 individuals identified from the study area, 2 matches were made to south Molokai (based on 11 photo-IDs), 3 matches to Molokini Crater (based on 11 photo-IDs) and 1 match to a southwest Maui sighting (based on 18 photo-IDs) (Fig. 4). No matches were found between the 290 individual manta rays from the
Maui study area and the 145 individuals photo-identified in waters off Kona on the Big Island, a transit distance of $\sim 150 \mathrm{~km}$ from the study area.

\section{Population structure}

The 290 photo-identified individuals were composed of 153 (53\%) males and $128(44 \%)$ females. Of these individuals, 9 were of unknown sex. The sex ratio did not differ significantly from parity (chi-square test, $\chi^{2}=1.112$, $\mathrm{df}=1, \mathrm{p}<0.292)$. At least $44 \%$ of the females were considered to be sexually mature based on the appearance of being pregnant or with mating scars. Among the males, $72 \%$ were considered sexually mature based on claspers extending beyond the pelvic fins, $26 \%$ were recorded as immature and $2 \%$ were never confirmed.

\section{Use of the aggregation area}

\section{Temporal trends}

It was rare to see manta rays during early morning surveys. The sighting rates (mean $\pm \mathrm{SD}$ ) were $1.40 \pm 3.24$, $4.17 \pm 4.25$ and $6.94 \pm 5.16$ manta rays per hour for morning, midday and afternoon surveys, respectively (Table 1). To eliminate the diurnal effect on sighting rates described previously, analyses of sighting rates incorporated only the 187 afternoon surveys.

Other variables affecting sighting rate

Survey month was a significant predictor of the mean sighting rate (Kruskal-Wallis test, $\chi^{2}=26.14$, df $=11$, $\mathrm{p}=0.006$; Table 5), with significantly greater sighting rates during the winter months $\left(\chi^{2}=19.35\right.$, $\mathrm{df}=1, \mathrm{p}<$ 0.001). For 2006, 2007 and 2008, during which surveys were conducted in both summer and winter months, mean sighting rates did not differ significantly $\left(\chi^{2}=\right.$ 0.91 , df $=2, p=0.634)$. Sighting rates were not significantly affected by visibility $\left(\mathrm{r}^{2}=0.031, \mathrm{p}=0.075\right)$ or tidal state $\left(\chi^{2}=5.616, \mathrm{df}=3, \mathrm{p}=0.132\right)$. 
Table 5. Manta alfredi. Number of surveys, sighting rates (mean $\pm \mathrm{SD}$ ), rate of new individuals, proportion of males and proportion of mating trains broken down by month and season for surveys in the afternoon. Both 'Sighting rate' and the 'Mean rate of new individuals' were significantly higher in the winter season when compared to the summer season $(p<0.05)$

\begin{tabular}{|lccccc|}
\hline Month & $\begin{array}{c}\text { No. of } \\
\text { surveys }\end{array}$ & $\begin{array}{c}\text { Sighting } \\
\text { rate }\end{array}$ & $\begin{array}{c}\text { Mating } \\
\text { trains }(\%)\end{array}$ & $\begin{array}{c}\text { Males } \\
(\%)\end{array}$ & $\begin{array}{c}\text { Mean rate of } \\
\text { new individuals }\end{array}$ \\
\hline Winter & & & & & \\
Nov & 14 & $7.73 \pm 5.24$ & 0 & $61 \pm 0.16$ & $0.25 \pm 0.18$ \\
Dec & 10 & $10.31 \pm 6.47$ & 10 & $57 \pm 0.07$ & $0.14 \pm 0.13$ \\
Jan & 13 & $11.13 \pm 7.29$ & 31 & $64 \pm 0.23$ & $1.40 \pm 1.49$ \\
Feb & 14 & $7.38 \pm 4.79$ & 43 & $54 \pm 0.24$ & $2.02 \pm 2.52$ \\
Mar & 10 & $9.37 \pm 7.80$ & 20 & $67 \pm 0.23$ & $1.40 \pm 1.96$ \\
Apr & 22 & $7.90 \pm 4.28$ & 32 & $58 \pm 0.23$ & $1.85 \pm 1.79$ \\
Overall & 83 & $\mathbf{8 . 7 6} \pm \mathbf{5 . 8 0}$ & $\mathbf{2 4}$ & $60 \pm 0.21$ & $\mathbf{1 . 7 9} \pm \mathbf{1 . 8 4}$ \\
& & & & & \\
Summer & & & 7 & $63 \pm 0.26$ & $0.45 \pm 0.87$ \\
May & 15 & $4.45 \pm 3.08$ & 13 & $49 \pm 0.30$ & $0.66 \pm 0.97$ \\
Jun & 16 & $6.67 \pm 4.36$ & 17 & $48 \pm 0.29$ & $1.35 \pm 1.55$ \\
Jul & 24 & $5.26 \pm 4.14$ & 17 & $54 \pm 0.28$ & $0.60 \pm 0.85$ \\
Aug & 17 & $3.40 \pm 2.88$ & 0 & 54.29 & $1.68 \pm 1.79$ \\
Sep & 19 & $6.78 \pm 3.95$ & 11 & $50 \pm 0.29$ \\
Oct & 13 & $6.49 \pm 5.04$ & 8 & $56 \pm 0.25$ & $0.67 \pm 0.64$ \\
Overall & 104 & $\mathbf{5 . 4 9} \pm \mathbf{4 . 0 5}$ & $\mathbf{1 0}$ & $53 \pm 0.28$ & $\mathbf{0 . 9 7} \pm \mathbf{1 . 3 1}$ \\
Grand total & 187 & $6.94 \pm 5.16$ & 16 & $56 \pm 0.25$ & $1.33 \pm 1.62$ \\
\hline
\end{tabular}

\section{Residency}

Of the 290 uniquely identified individuals, 78 (27\%) were observed only once, $212(73 \%)$ were observed more than once, 198 (68\%) were resighted within a $1 \mathrm{yr}$ period and 95 (33\%) were resighted across multiple years (Fig. 5). Resightings were made on $76 \%$ of the females, $74 \%$ of the males, $78 \%$ of the adult males and $59 \%$ of the juvenile males. Of the top 10 most resighted individuals, 6 were male and 4 were female. The most resighted individual was an adult male, seen 41 times between April 2005 and April 2009. The most re- sighted female was sexually mature and seen 30 times between April 2005 and December 2008.

The mean period between resightings for all individuals was $181 \pm 195 \mathrm{~d}$, ranging from a single day to as long as $3.6 \mathrm{yr}$. For the highest resighted individual, 31 $(78 \%)$ resightings had a lag period of less than 2 mo, but on 2 occasions his lag periods were 7 and 10 mo in duration.

LIR calculations indicate that adult females tended to reside longer in the study area compared with adult males (Fig. 6). The best fitting model for both adult males and adult females was a model described by a system where emigration, reimmigration and mortality is occurring in the study population. Models of adult male and adult female manta ray residency were fitted to the residency rate data using QAIC methods to determine the best model (Table 6).

\section{Reproduction}

Mating trains were observed during 10 months of the year, with most surveys containing mating trains occurring between December and April. Significantly more mating trains were observed during the winter $(24 \%)$ compared with the summer $(10 \%)$ (chi-square test, $\chi^{2}=195.2$, df $=1, p<0.001$; Table 5). The proportion of males to females during winter months (0.60) was not significantly different than that during the summer months (0.53) (Kruskal-Wallis test, $\chi^{2}=3.65$, df $=1, \mathrm{p}=0.056 ;$ Table 5).

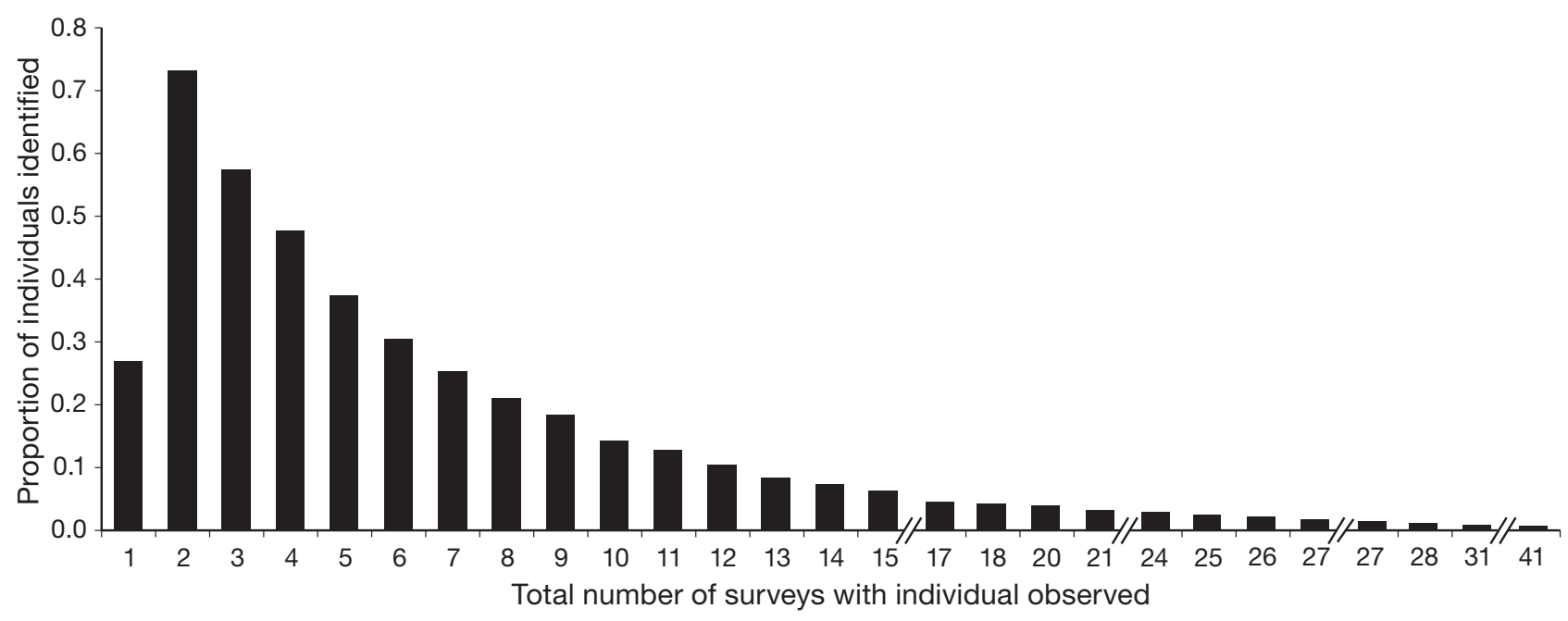

Fig. 5. Manta alfredi. Proportion of individuals identified plotted against the number of surveys in which they were observed 


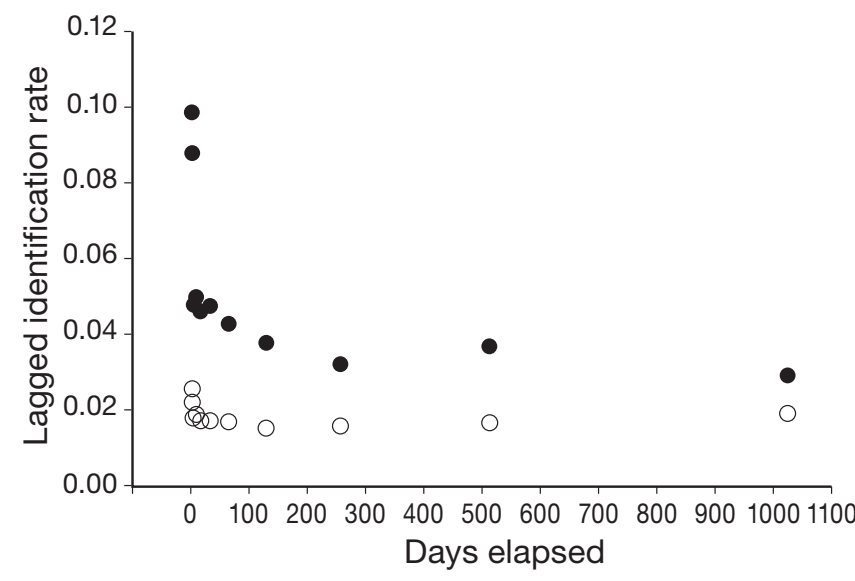

Fig. 6. Manta alfredi. Lagged identification rates for adult male $(\mathrm{O})$ and female $(\bullet)$ manta rays

New individuals

The overall mean rate of newly encountered manta rays was 1.33 per hour of observation. This rate decreased each year from 2.41 in 2005 to 0.77 in 2008, but increased again in 2009 to 1.02 (Table 5). Month played a significant role in the rate of new individuals observed (Kruskal-Wallis test, $\chi^{2}=23.596$, df $=11, \mathrm{p}=$ $0.015)$, with a higher rate of new individuals observed during the winter months $\left(\chi^{2}=10.355\right.$, df $=1, p=0.001$; Table 5).

\section{Threats}

Natural

A total of 70 individuals $(24 \%)$ had an injury that appeared to have been caused by a shark attack based on wound characteristics described for shark predation on marine mammals and turtles (Corkeron et al. 1987, Heithaus 2001, Heithaus et al. 2002). Males and females were both equally likely to have these injuries (chi-square test, $\chi^{2}=1.389$, df $=1, p=0.239$ ), but juve-

Table 6. Manta alfredi. Models of adult male and adult female residency fitted to the residency rate data using QAIC methods to determine the best model (in bold). QAIC model fitting was chosen over AIC model-fitting because of variance overdispersion

\begin{tabular}{|lcc|}
\hline \multirow{2}{*}{ Model } & \multicolumn{2}{c|}{ QAIC } \\
& Males & Females \\
\hline Closed & 8488.6 & 13030.4 \\
Emigration + Mortality & 8490.1 & 13011.3 \\
Emigration + Reimmigration & 8491.7 & 13015.6 \\
Emigration + Reimmigration + Mortality & $\mathbf{8 4 8 4 . 3}$ & $\mathbf{1 2 9 9 7 . 4}$ \\
\hline
\end{tabular}

nile males were significantly less likely to possess these injuries compared with adult males $\left(\chi^{2}=7.509\right.$, $\mathrm{df}=1, \mathrm{p}=0.023)$. Only a single juvenile $(3 \%)$ had shark-related injuries compared with 31 (30\%) adult males. Because juvenile females could not be determined, the proportion of injuries in adult and juvenile females could not be compared.

\section{Anthropogenic}

Twenty-eight individuals (10\%) had an amputated or disfigured, non-functioning cephalic fin. The proportion of males and females with cephalic fin injuries were not significantly different (chi-square test, $\chi^{2}=$ 1.567 , $\mathrm{df}=1, \mathrm{p}=0.211$ ). The proportion of adult males and juvenile males with cephalic fin injuries were also not significantly different $\left(\chi^{2}=1.676, \mathrm{df}=1, \mathrm{p}=0.433\right)$.

Eight individuals had physical evidence of entanglement in fishing line. These included 2 individuals with fish hooks embedded in the cephalic fin, 2 with monofilament line wrapped around the cephalic fin, 2 with clear injuries where line had begun to cut partway through the cephalic fin and 2 with visible scars from line that had been wrapped around the cephalic or pectoral fin.

\section{DISCUSSION}

\section{Abundance and survivorship}

The population of manta rays utilizing the Maui aggregation site consisted of at least 290 individuals, and the rate of new individuals shows no sign of leveling off, suggesting that the overall population is much larger than all individuals identified. Other reported population sizes include 185 unique individuals identified over a 20 yr period from an aggregation site off the Yaeyama Islands in Japan, and 54 unique individuals identified over a $7 \mathrm{yr}$ period off the island of Yap in the Western Pacific (Homma et al. 1999). An estimated 890 individuals, of which 449 individuals were identified over a 5 yr period were reported for a Manta alfredi population along the west coast of Mozambique, Africa (Marshall 2009). In areas where anthropogenic influences are not impeding population growth, the size of the local population may reflect local food availability and the carrying capacity this resource can sustain. For example, the presence of manta rays around the atolls of the Republic of the Maldives coincides with the seasonally 
alternating monsoon currents, supplying rich zooplankton blooms that support a manta ray population numbering into the thousands (Anderson et al. 2011).

It was not possible to reliably estimate manta ray abundance for the entire $5 \mathrm{yr}$ period using markrecapture methods because the assumption of a closed population could not be met. Instead, the population size was estimated during 5 intense sampling periods for each of $5 \mathrm{yr}$. These results indicate a population that is moving into and out of the vicinity of the Maui aggregation area with a varying portion of the total population temporarily resident at the study site at any given time. The number of manta rays using the study area during these 3 to 4 mo sampling periods could be as high as 230 individuals.

The high apparent survival rates we obtained (especially during the first 2 intervals) are notable. From a purely statistical perspective, apparent survival rates can sometimes be uninformative because one does not know how much to attribute to mortality versus permanent emigration. With a highly mobile species such as the manta ray, sampled at just one focal site, we anticipated that emigration could be quite large. Instead, the high apparent survival estimates obtained constrain the uncertainty about the fate of the animals. They also demonstrate that although temporary migration away from the study site is likely quite common, long-term fidelity to the site is high. From a conservation perspective, the high survival rate of adults is also encouraging. As mortality and emigration cannot be differentiated, the somewhat lower survival rate observed between the third and fourth sampling periods could be an indication of higher mortality or more emigration, or simply a statistical artifact of the sampling (this interval occurring near the end of the study).

\section{Individual movements}

Photo-identification matches combined with tracks from acoustically tagged animals provide evidence that individuals from the study site are capable of moving between the 4 islands that represent the Maui County area (Maui, Molokai, Lanai and Kahoolawe), with distances between these neighboring islands ranging from 11 to $15 \mathrm{~km}$. The closest distance between the island of Hawaii and the island of Maui is $49 \mathrm{~km}$, which would seem be within the range of attainment for individuals in this Maui population. Manta alfredi in Japan were reported to travel distances of $350 \mathrm{~km}$ (Homma et al. 1999), and individuals from a population in the Maldives reportedly traveled $160 \mathrm{~km}$ (Kitchen-Wheeler 2008). However, the absence of photo-identification matches between the Maui and Kona populations, for which individual identities have been well documented by commercial dive operators for the past $10 \mathrm{yr}$, brings into question whether movement between these islands is occurring. The deepest area transited by one of the acoustically tracked individuals was $360 \mathrm{~m}$. The $2000 \mathrm{~m}$ depth in the middle of the Alenuihaha Channel could present a barrier preventing individuals from crossing Maui to the Big Island. A more likely explanation is that sufficient resources exist within the 4 -island region to sustain the Maui population, making the transit unnecessary. Species such as Cuvier's beaked whales Ziphius cavirostris and Blainville's beaked whales Mesoplodon densirostris, spinner dolphins Stenella longirostris and bottlenose dolphins Tursiops truncatus have been reported to have independent island-associated stocks among the main Hawaiian Islands (Andrews et al. 2006, McSweeney et al. 2007, Baird et al. 2009).

The greatest depth needed to transit from Molokai to Oahu is $600 \mathrm{~m}$. If depth does not represent an interisland barrier, future research should compare individuals photo-identified on Oahu with those from the Maui study area. Additional acoustic tracking of individuals could help to confirm whether these individuals are crossing the deep channels to neighboring islands outside the Maui County area.

\section{Population structure}

The sex ratio in the present study was not significantly different from parity, whereas Marshall \& Bennett (2010) reported a strong female-biased sex ratio (1:3.5) within a population off the eastern coast of Mozambique. The attractiveness of an aggregation area may vary according to the sex or age class of an individual. Aggregation areas in close proximity to suitable pupping grounds may be more favorable to pregnant females (Marshall \& Bennett 2010). The lack of female bias in this aggregation area may reflect the absence of a nearby birthing area.

The DW of 154 different individuals from this population was measured using paired-laser photogrammetry (Deakos 2010), and all values were $>2.5 \mathrm{~m}$. The smallest free-swimming individuals for both Manta birostris and $M$. alfredi have been reported between 1.2 and $1.5 \mathrm{~m}$ DW (Bigelow \& Schroeder 1953, Marshall et al. 2008). This suggests that very young animals in the Maui population may be segregated geographically and staying out of the study area, making them unavailable for sighting. In some coastal shark species, females seek out discrete inshore habitats where they give birth and the young spend their first weeks, months or years of life protected from predation by larger sharks (e.g. Castro 1993). Very young individuals in this population may exhibit similar behavior. 
This age class may represent a significant portion of the population that is not accounted for in the population estimate.

\section{Use of the aggregation area}

Frequent resightings of individuals within and across years support long-term site fidelity to the Maui study area. Although site fidelity was highly variable between individuals, males and females, or adult males and juvenile males, were equally likely to revisit the study site. The times between resightings ranged from $1 \mathrm{~d}$ to over $3 \mathrm{yr}$, with an average of $\sim 6$ mo between sightings. Even individuals with the strongest fidelity to the study site, on occasion, were not resighted for periods of 6 mo or more. This is consistent with animals residing in the area for a period of time before dispersing to a new area. The absence from the study area for long durations may be a product of a decrease in food resources or potential mates in the area during that period. Caution should be taken when interpreting these results because effort was not continuous and individuals could have been present in the study area when surveys were not conducted.

Time of day and the time of year (month and season) were the best predictors of manta ray sighting rates. They were typically absent in the early morning with sighting rates increasing as the day progressed. The 2 individual manta rays equipped with acoustic tags both moved offshore and out of the study area after sunset. Because both individuals were part of a mating train when tagged, it is unclear whether these offshore movements were representative of all individuals or specific to individuals in mating trains. Both individuals remained in the study area for several hours before moving offshore, making it unlikely that their movements were a response to being tagged.

This diurnal trend may be due to manta rays moving out of the study area at night to feed, as they were never seen feeding while in the study area. Whether these animals were feeding during the night was not confirmed. Although zooplankton distribution and abundance can be highly variable across space and time (Greene et al. 1998), certain changes in the vertical abundance of zooplankton, termed diel vertical migration, can be predicted (for review see Hays 2003). Planktivorous elasmobranchs such as basking sharks Cetorhinus maximus and whale sharks Rhincodon typus can take advantage of these predictable diel trends by resting more during the day and foraging more at night when the plankton moves closer to the surface (Sims et al. 2005, Rowat et al. 2007). By feeding at night, manta rays could be taking advantage of more easily accessible euphausiid and copepod concentra- tions. Further research is needed to better understand when and where this population is feeding.

Although mating trains were observed during 10 mo of the year, most occurred during the winter months, primarily January through April. This was also the time when the proportions of new individuals sighted during a survey were highest. It is possible that, during the reproductive season, more individuals visit the aggregation area in search of mates rather than for use of the cleaning stations. A mating system is based on the potential of one sex to monopolize key resources or mates of the limiting sex (Emlen \& Oring 1977). The limiting sex is usually more heavily invested in parental care, and the greater the imbalance, the more intrasexual competition exists between members of the other sex (Darwin 1871). Female manta rays are likely the limiting sex as they provide the only parental investment in the form of a 12 mo gestation period, and multiple males appear to compete for access to a single female in a mating train (Yano et al. 1999). The dispersion of females, or resources essential to females, limits the ability for a male to monopolize multiple females. A male-dominant polygynous mating system could explain shorter residency times calculated for males, who may move more frequently between aggregation areas in search of reproductively available females. Adult females may benefit from residing longer in a popular aggregation area where they may have a greater selection of potential mates, provided food resources are also available nearby.

\section{Threats}

Both natural threats and anthropogenic threats were documented in this population. Large sharks (Homma et al. 1999) and killer whales Orcinus orca (Visser \& Bonoccorso 2003) have been reported to prey on manta rays. Because killer whales are extremely rare in Hawaiian waters (Mobley et al. 2001), the most likely predator would be large sharks such as the common tiger shark Galeocerdo cuvier. Approximatey 1 in 4 individuals showed injuries likely caused from a shark attack. Although males and females were equally likely to possess these injuries, adult males were 10 times more likely to have these injuries compared with juvenile males. This study suggests that young manta rays segregate geographically, possibly residing in areas that make them less prone to shark predation during the early years of development, whereas adults foraging in deeper water may be more prone to such predation. The proportional difference could also be an artifact of adults having more exposure to sharks during their lifetime or they may be more likely to survive a shark attack because of their larger body size. How- 
ever, if shark attacks on juveniles are fatal, these would go undetected.

One out of 10 manta rays in the population had an amputated or non-functioning cephalic fin, most likely due to entanglement in monofilament line. Considering the function of the cephalic fins to guide food into the mouth during feeding, an animal reduced to a single cephalic fin would likely suffer a reduction in feeding efficiency. Individuals in this population with only a single functioning cephalic fin appeared healthy, but further research should investigate how the absence of a cephalic fin affects the size, growth rate and reproductive success of these individuals.

All amputated cephalic fins had straight edge cuts, consistent with being severed with line. Some deformed cephalic fins had straight cuts halfway through the fin, most likely due to having shed the line before the fin was completely severed. Shark predation as the cause of cephalic fin damage seems unlikely, as of the 70 individuals with shark attack scars, 65 had scars either on the posterior part of their body or on the wing tip. Only 5 individuals possessed attack scars anterior to the midline of the body. This suggests that most attacks are occurring from behind or from the side. Additionally, 8 individuals were observed with either fish hooks embedded into their cephalic fins, fishing line wrapped around a cephalic fin or fishing line scars around a cephalic fin or the pectoral fin, providing further evidence that entanglement in fishing lines is a significant threat. Further research is needed to determine the impaired fitness of a manta ray reduced to only a single cephalic fin. This could be achieved by monitoring their growth and reproductive success over time.

Manta rays have also been known to die from entanglement in boat anchor lines (Bigelow \& Schroeder 1953) and mooring lines. Two manta ray entanglements in mooring lines were documented on video in Hawaii. The first was reported inside Molokini Crater, Maui, on 12 June 2007 (A. Cummins pers. comm.), and the second off Kona, Hawaii, on 19 June 2009 (K. Osada pers. comm.). Both manta rays perished and were consumed by sharks immediately thereafter.

Additional acoustic tracking could assist in determining areas frequented by manta rays that may be heavily fished and pose a higher risk of entanglement. Managing fishing practices in these areas or simply educating fishers who utilize these areas could help to reduce the frequency of manta ray entanglements.

Several manta ray aggregation sites worldwide are being utilized commercially to put paying clients in the water to swim with manta rays. Unregulated, these operations can impose undue stress on the local manta ray population, potentially causing the animals to abandon the area. Sustained pressure from divers, snorkelers, boaters and jet skiers visiting a manta ray aggregation site in Bora Bora, French Polynesia, reportedly caused the manta rays to completely abandon this area (de Rosemont 2008). The biological significance of displacing manta rays from these aggregation sites is unknown and worthy of investigation. A study conducted by Semeniuk (2009) indicated that interaction between tourists and a wild population of southern stingrays Dasyatus americana resulted in higher parasite loads, higher injury rates and suppression of the immune system in the stingrays, putting their longterm survival at serious risk.

Recent success in Japan's manta ray captivity program (Uchida et al. 2008) has sparked global interest from aquariums looking to add manta rays to their exhibits. In certain aggregation areas where manta rays are easily accessible, and where no regulatory protection exists, populations, especially those that are small and geographically isolated, may be exposed to indiscriminant non-sustainable extraction of individuals for profit.

\section{Population management}

In many parts of the world, measures have been taken to reduce anthropogenic threats on local manta ray populations. For example, codes of conduct for manta ray dive operators have been implemented in Kona, Hawaii, Western Australia (Daw \& McGregor 2008), Mozambique, Bora Bora, French Polynesia (de Rosemont 2008) and the Maldives (Anderson et al. 2011). Elements of the code include minimizing the number of divers around the manta rays, keeping divers in tight controlled groups, restricting the touching of animals and using approach methods that minimize stress on the manta rays. In Mozambique, mooring balls are banned in areas where manta rays are known to aggregate, and boats are required to minimize their speed. Marine protected areas have been established in the Maldives, Mexico, Mozambique and Yap to help eliminate fishing pressure and provide a safe refuge for manta rays. In 2009, the State of Hawaii passed a law making it illegal to intentionally kill or extract manta rays within state waters, with an exception given to persons granted a special take permit.

\section{CONCLUSIONS}

The findings of this study are consistent with a population of more than 290 manta rays moving into and out of the Maui study area with a varying portion of the total population temporarily resident in the study area 
at any given time. Although strong site fidelity to the study area exists, 4 individuals were confirmed to move to another island within the Maui County area. This may indicate a population that ranges throughout Maui County but that is geographically distinct from its neighboring island populations. Further research using active and passive tracking and genetics is needed to confirm the existence of independent Hawaiian island stocks of Manta alfredi.

The biological significance of the study area is not well understood, but it appears to be an important staging area where individuals from the population make routine year-round visits to either rid themselves of parasites or to find available mates. The absence of very young individuals $(<2.5 \mathrm{~m} \mathrm{DW})$ and a biased sex ratio towards adult males indicates that not all individuals in the population make use of the area equally and segregation is occurring based on age class and sex. The predominance of adult males and the high frequency of mating trains observed indicate the study area may also be a significant mating area, primarily between the months of December and April.

If island-associated Manta alfredi populations are indeed geographically independent from neighboring stocks, with little or no transfer occurring between individuals, regional management of these stocks is needed to deal with specific threats that are unique to each region. Small, isolated populations can be at serious risk of rapid and unrecoverable decline (Musick 1999), and the frequent occurrence of large aggregations of manta rays within a small area makes them even more vulnerable to localized anthropogenic impacts.

The greatest immediate threat to this population appears to be entanglement in monofilament fishing line, which appears to result in disablement or dismemberment of the cephalic fin, likely impacting an individual's feeding efficiency. Anticipated threats in the near future include unregulated swim-with-manta-ray programs, adding increased pressure on animals utilizing this natural aggregation area, and entanglement in proposed mooring lines for this area.

The recent differentiation of the genus Manta into 2 separate species raises new concerns about anthropogenic influences on highly resident populations. Because of the slow population growth and low fecundity typical of elasmobranchs (Holden 1974), monitoring of changes in population size, population growth and impact on these parameters from anthropogenic sources is recommended. An understanding of population characteristics and basic ecological information is needed on a regional basis.

Acknowledgements. We thank J. Whitney, A. Ligon and E. Lyman for support with data collection, and R. Deakos, S. Spitz and B. Brainstetter for assistance with paired-laser pho- togrammetry calibrations. Regarding the active tracking portion of this study, many thanks go to T. Clark for his invaluable expertise; J. Whitney and L. James for assistance with tracking; the University of Hawaii Zoology department for supplying the Vemco VR100 acoustic receiver and the VH110 directional hydrophone; and Ultimate Whale Watching Adventures for providing the research vessel. S. Yin, L. Herman and anonymous reviewers provided valuable feedback on earlier versions of this manuscript. The Change Happens Foundation contributed funds towards the purchase of 3 Vemco V-16 acoustic transmitters. Special thanks go to $\mathrm{H}$. Whitehead for the development of SOCPROG and for advice on computational analysis. Thanks to J. Mobley for assistance with animal care permits. Research was conducted under the University of Hawaii Animal Care \& Use Committee (protocol no. 08-591-2, assurance no. A3423-01).

\section{LITERATURE CITED}

Adams J, Speakman T, Zolman E, Schwacke L (2006) Automating image matching, cataloging, and analysis for photo-identification research. Aquat Mamm 32:374-384

Alava MNR, Dolumbaló ERZ, Yaptinchay AA, Trono RB (2002) Fishery and trade of whale sharks and manta rays in the Bohol Sea, Philippines. In: Fowler SL, Reed TM, Dipper FA (eds) Elasmobranch biodiversity, conservation and management: proceedings of the international seminar and workshop. Occasional paper of the IUCN Species Survival Commission, Sabah, Malaysia, p 132-148

Anderson D, Burnham K, Thompson W (2000) Null hypothesis testing: problems, prevalence, and an alternative. J Wildl Manag 64:912-923

Anderson R, Adam M, Kitchen-Wheeler A, Stevens G (2011) Extent and economic value of manta ray watching in Maldives. Tourism Mar Environ 7:15-27

Andrews K, Karczmarski L, Au W, Rickards S, Vanderlip C, Toonen R (2006) Patterns of genetic diversity of the Hawaiian spinner dolphin (Stenella longirostris). Atoll Res Bull 543:65-73

Baird R, Gorgone A, McSweeney D, Ligon A and others (2009) Population structure of island-associated dolphins: evidence from photo-identification of common bottlenose dolphins (Tursiops truncatus) in the main Hawaiian Islands. Mar Mamm Sci 25:251-274

Beebe W, Tee-Van J (1941) Manta hamiltoni (Newman). Zool J Linn Soc 26:274-278

Bejder L, Fletcher D, Bräger S (1998) A method for testing association patterns of social animals. Anim Behav 56: 719-725

Bigelow H, Schroeder WC (1953) Fishes of the western North Atlantic. Sawfishes, guitarfishes, skates, rays, and chimaeroids. Mem Sears Found Mar Res 1:500-514

> Brault S, Caswell H (1993) Pod-specific demography of killer whales (Orcinus orca). Ecology 74:1444-1454

Calambokidis J, Steiger G, Evenson J, Flynn K and others (1996) Interchange and isolation of humpback whales off California and other North Pacific feeding grounds. Mar Mamm Sci 12:215-226

Castro J (1993) The shark nursery of Bulls Bay, South Carolina, with a review of the shark nurseries of the southeastern coast of the United States. Environ Biol Fishes 38:37-48

Clark TB (2001) Population structure of Manta birostris (Chondrichthyes: Mobulidae) from the Pacific and Atlantic Oceans. MS thesis, Texas A\&M University, Galveston, TX

Compagno LJV (1984) FAO species catalogue, Vol. 4. Sharks of the world. An annotated and illustrated catalogue of 
shark species known to date. Part 2. Carcharhiniformes. FAO Fish Syn 125:251-655

Corkeron P, Morris R, Bryden M (1987) Interactions between bottlenose dolphins and sharks in Moreton Bay, Queensland. Aquat Mamm 13:109-113

Compagno L (1999) Systematics and body form. In: Hamlett WC (ed) Sharks, skates and rays: the biology of elasmobranch fishes. John Hopkins University Press, Baltimore, MD, p 1-42

Darwin C (1871) The descent of man, and selection in relation to sex, 1 \& 2. Appleton, New York, NY

Daw B, McGregor F (2008) Management of manta ray ( $M$. birostris) interactive tours in the shallow lagoonal waters of Ningaloo Reef, Western Australia: a global benchmark for tourism interactions. In: Donnelly MA (ed) 2008 Joint Meeting of Ichthyologists and Herpetologists. Montreal, Canada, p 106

de Rosemont M (2008) Observation and sighting description of the Manta birostris, in Bora Bora Island (French Polynesia, South Pacific). In: Donnelly MA (ed) 2008 Joint Meeting of Ichthyologists and Herpetologists. Montreal, Canada, p 106

> Deakos M (2010) Paired-laser photogrammetry as a simple and accurate system for measuring the body size of freeranging manta rays Manta alfredi. Aquat Biol 10:1-10

Dewar H (2002) Preliminary report: manta harvest in Lamakera. Report from the Pfleger Institute of Environmental Research and the Nature Conservancy

> Dewar H, Mous P, Domeier M, Muljadi A, Pet J, Whitty J (2008) Movements and site fidelity of the giant manta ray, Manta birostris, in the Komodo Marine Park, Indonesia. Mar Biol 155:121-133

Dulvy N, Reynolds J (2002) Predicting extinction vulnerability in skates. Conserv Biol 16:440-450

Dulvy N, Baum J, Clarke S, Compagno L and others (2008) You can swim but you can't hide: the global status and conservation of oceanic pelagic sharks and rays. Aquat Conserv 18:459-482

Emlen ST, Oring LW (1977) Ecology, sexual selection, and the evolution of mating systems. Science 197:215-223

Fowler H (1941) The George Vanderbilt Oahu Survey: the fishes. Proc Acad Nat Sci Phila 93:247-279

Graham R, Roberts C (2007) Assessing the size, growth rate and structure of a seasonal population of whale sharks (Rhincodon typus Smith 1828) using conventional tagging and photo identification. Fish Res 84:71-80

Greene C, Wiebe P, Pelkie C, Benfield M, Popp J (1998) Three-dimensional acoustic visualization of zooplankton patchiness. Deep-Sea Res II 45:1201-1217

Hays G (2003) A review of the adaptive significance and ecosystem consequences of zooplankton diel vertical migrations. Hydrobiologia 503:163-170

Heithaus M (2001) Shark attacks on bottlenose dolphins (Tursiops aduncus) in Shark Bay, Western Australia: attack rate, bite scar frequencies, and attack seasonality. Mar Mamm Sci 17:526-539

Heithaus M, Frid A, Dill L (2002) Shark-inflicted injury frequencies, escape ability, and habitat use of green and loggerhead turtles. Mar Biol 140:229-236

Hoenig J, Gruber S (1990) Life-history patterns in the elasmobranchs: implications for fisheries management. NOAA Tech Rep NMFS 90:1-16

Holden MJ (1974) Problems in the rational exploitation of elasmobranch populations and some suggested solutions. In: Jones FRH (ed) Sea fisheries research. Wiley, New York, NY, p 117-137

Homma K, Maruyama T, Itoh T, Ishihara H, Uchida S (1999)
Biology of the manta ray, Manta birostris Walbaum, in the Indo-Pacific. In: Seret B, Sire JY (eds) Indo-Pacific fish biology. Proceedings of the Fifth International Conference on Indo-Pacific fishes, Noumea, 1997. Ichthyological Society of France, Paris, p 209-216

Jones A, Hall N, Potter I (2008) Size compositions and reproductive biology of an important bycatch shark species (Heterodontus portusjacksoni) in south-western Australian waters. J Mar Biol Assoc UK 88:189-197

Kashiwagi T, Ito T, Ovenden J, Bennett M (2008) Population characteristics of Manta birostris observed in Yaeyama, Okinawa, Japan, 1987-2006. In: Donnelly MA (ed) 2008 Joint Meeting of Ichthyologists and Herpetologists. Montreal, Canada, p 205

Kitchen-Wheeler AM (2008) Migration behaviour of the giant manta (Manta birostris) in the central Maldives atolls. In: Donnelly MA (ed) 2008 Joint Meeting of Ichthyologists and Herpetologists. Montreal, Canada, p 213

Langtimm C, Beck C, Edwards H, Fick-Child K, Ackerman B, Barton S, Hartley W (2004) Survival estimates for Florida manatees from the photo-identification of individuals. Mar Mamm Sci 20:438-463

Last P, Stevens J (1994) Sharks and rays of Australia. CSIRO Publishing, Melbourne

> Lebreton J, Burnham K, Clobert J, Anderson D (1992) Modeling survival and testing biological hypotheses using marked animals: case studies and recent advances. Ecol Monogr 62:67-118

Losey G Jr (1972) The ecological importance of cleaning symbiosis. Copeia 1972:820-833

Marshall AD (2009) Biology and population ecology of Manta birostris in southern Mozambique. PhD thesis, University of Queensland, Brisbane St Lucia

Marshall AD, Ishihara H, Dudley SFJ, Clark TB, Jorgensen S, Smith WD, Bizzarro JJ (2006) Manta birostris. In: IUCN (2010) IUCN Red List of Threatened Species. Available at www.iucnredlist.org

> Marshall AD, Bennett MB (2010) Reproductive ecology of the reef manta ray Manta alfredi in southern Mozambique. J Fish Biol 77:169-190

Marshall AD, Pierce SJ, Bennett MB (2008) Morphological measurements of manta rays (Manta birostris) with a description of a foetus from the east coast of Southern Africa. Zootaxa 1717:24-30

Marshall AD, Compagno L, Bennett MB (2009) Redescription of the genus Manta with resurrection of Manta alfredi (Krefft, 1868) (Chondrichthyes; Myliobatoidei; Mobulidae). Zootaxa 2301:1-28

McSweeney D, Baird R, Mahaffy S (2007) Site fidelity, associations, and movements of Cuvier's (Ziphius cavirostris) and Blainville's (Mesoplodon densirostris) beaked whales off the island of Hawai'i. Mar Mamm Sci 23:666-687

Mobley J, Mazzuca L, Craig A, Newcomer M, Spitz S (2001) Killer whales (Orcinus orca) sighted west of Nihau, Hawaii. Pac Sci 55:301-304

Musick J (1999) Ecology and conservation of long-lived marine animals. Am Fish Soc Symp 23:1-10

Musick J, McMillan B (2002) The shark chronicles. Henry Holt, New York, NY

Nelson J (1984) Fishes of the world. John Wiley \& Sons, New York, NY

Nishida K (1990) Phylogeny of the suborder Myliobatoidei. Mem Fac Fish 37:1-108

- Notarbartolo-di-Sciara G (1987) A revisionary study of the genus Mobula Rafinesque, 1810 (Chondrichthyes: Mobulidae) with the description of a new species. Zool J Linn Soc 91:1-91 
Otis D, Burnham K, White G, Anderson D (1978) Statistical inference from capture data on closed animal populations. Wildl Monogr 62:3-135

Paulin C, Habib G, Carey C, Swanson P, Voss G (1982) New records of Mobula japanica and Masturus lanceolatus, and further records of Luvaris imperialis (Pisces: Mobulidae, Molidae, Louvaridae) from New Zealand. NZ J Mar Freshw Res 16:11-17

Pratt H, Casey J (1990) Shark reproductive strategies as a limiting factor in directed fisheries, with a review of Holden's method of estimating growth parameters. NOAA Tech Rep 90:97-109

Rexstad E, Burnham K (1991) Users guide for interactive program CAPTURE. Colorado Cooperative Fish and Wildlife Research Unit, Colorado State University, Fort Collins, CO

Romanov E (2002) Bycatch in the tuna purse-seine fisheries of the western Indian Ocean. Fish Bull 100:90-105

Rowat D, Meekan M, Engelhardt U, Pardigon B, Vely M (2007) Aggregations of juvenile whale sharks (Rhincodon typus) in the Gulf of Tadjoura, Djibouti. Environ Biol Fishes 80:465-472

Semeniuk C, Bourgeon S, Smith S, Rothley K (2009) Hematological differences between stingrays at tourist and nonvisited sites suggest physiological costs of wildlife tourism. Biol Conserv 142:1818-1829

Sims D, Southall E, Tarling G, Metcalfe J (2005) Habitat specific normal and reverse diel vertical migration in the plankton feeding basking shark. J Anim Ecol 74: 755-761

Editorial responsibility: Hans Heinrich Janssen, Oldendorf/Luhe, Germany
Uchida S, Toda M, Matsumoto Y (2008) Captive records of manta rays in Okinawa Churaumi Aquarium. In: Donnelly MA (ed) 2008 Joint Meeting of Ichthyologists and Herpetologists. Montreal, Canada, p 397

Visser IN, Bonoccorso FJ (2003) New observations and a review of killer whale (Orcinus orca) sightings in Papua New Guinea waters. Aquat Mamm 29:150-172

White G, Burnham K (1999) Program MARK: survival estimation from populations of marked animals. Bird Study 46: 120-138

White WT, Giles J, Dharmadi, Potter IC (2006) Data on the bycatch fishery and reproductive biology of mobulid rays (Myliobatiformes) in Indonesia. Fish Res 82:65-73

Whitehead H (2001) Analysis of animal movement using opportunistic individual identifications: application to sperm whales. Ecology 82:1417-1432

Whitehead H (2007) Selection of models of lagged identification rates and lagged association rates using AIC and QAIC. Comm Statist Simulation Comput 36:1233-1246

Whitehead H (2009) SOCPROG programs: analysing animal social structures. Behav Ecol Sociobiol 63:765-778

Whitley GP (1936) The Australian devil ray, Daemomanta alfredi (Krefft), with remarks on the superfamily Mobuloidea (Order Batoidei). Aust Zool 8:164-184

Würsig B, Jefferson T (1990) Methods of photo-identification for small cetaceans. Rep Int Whal Comm 12:43-52

> Yano K, Sato F, Takahashi T (1999) Observations of mating behavior of the manta ray, Manta birostris, at the Ogasawara Islands, Japan. Ichthyol Res 46:289-296

Submitted: October 4, 2010; Accepted: February 11, 2011 Proofs received from author(s): May 2, 2011 